\title{
Issues in Development
}

\section{Identification of Small Molecules from Human Embryonic Stem Cells Using Metabolomics}

\author{
GABRIELA G. CEZAR, ${ }^{1}$ JESSICA A. QUAM, ${ }^{1,6}$ ALAN M. SMITH, \\ GUILHERME J.M. ROSA, ${ }^{2}$ MARIAN S. PIEKARCZYK ${ }^{3}$ JAMES F. BROWN, ${ }^{4}$ \\ FRED H. GAGE, ${ }^{5}$ and ALYSSON R. MUOTRI ${ }^{5}$
}

\begin{abstract}
Metabolomics enables the discovery of small molecules that may serve as candidate biomarkers of pharmacological efficacy or toxicity. Biochemical pathways of human development are likely active in human embryonic stem (hES) cells and derivatives, since they recapitulate organogenesis in vitro. We hypothesized that small molecules could be measured from undifferentiated hES cells and hES cell-derived neural precursors (hNPs) using metabolomics and that these compounds are altered in response to known disruptors of human development. Metabolite profiling was performed in hES cells and hNPs after exposure to valproate, an inducer of neurodevelopmental disorders. Kynurenine, an intermediate in tryptophan metabolism, and other small molecules in glutamate metabolism were significantly upregulated in response to valproate. Thus, for the first time, we have been able to measure and identify small molecules secreted from hES cells and cells derived from hES cells. The hES cell metabolome may thus serve as a source of candidate biomarkers to predict or measure pharmacological efficacy or toxic response.
\end{abstract}

\section{INTRODUCTION}

$\mathbf{H}$ UMAN EMBRYONIC STEM (hES) CELLS are pluripotent, self-renewing cells isolated directly from preimplantation human embryos (1) that can differentiate into multiple functional cell types (2-5). Thus, hES cells emulate early human development and have the potential to serve as an in vitro model for several human diseases. Despite extensive progress in the field, there have not been any studies to detect the dynamic set of small molecules produced by hES cells, i.e., the hES cell metabolome. Identification of small molecules from hES cells paves the way for novel applications of these cells in biomedical research, such as discovery of candidate biomarkers for pharmaceutical efficacy and toxicity screens or synthesis of stem cell-specific chemicals. A biomarker is a biochemical feature that can be used to predict, diagnose, or measure the progress of disease or toxic response. hES cells are the first research model derived directly from the human embryo, therefore these cells provide a groundbreaking opportunity to identify biomarkers for early human developmental disorders. Small molecules measured by metabolomics, may serve as candidate biomarkers for these disorders. Discovery of small molecules in hES cells also unravels pathways that participate in cellular response to drugs because these metabolites are precursors, intermediates, or end products of orchestrated biochemical circuits.

The cellular metabolome, or the global profile of metabolites, is a product of health or disease/insult states

\footnotetext{
${ }^{1}$ Department of Animal Sciences and ${ }^{2}$ Department of Dairy Sciences, University of Wisconsin-Madison, Madison, WI 53706.

${ }^{3}$ WiCell Research Institute, Madison, WI 53707.

${ }^{4}$ University of Wisconsin-Madison Biotechnology Center, Madison, WI 53706.

${ }^{5}$ Laboratory of Genetics, The Salk Institute for Biological Studies, La Jolla, CA 92037.

${ }^{6}$ These authors contributed equally to this work.
} 
(6). Metabolomics is particularly sensitive to environmental effects in comparison to other "omics" (7). Smallmolecule metabolites can be measured by nuclear magnetic resonance (NMR) (8) or mass spectrometry (9). Mass spectrometry is a standardized and well-established technology for the detection of small molecules. It is more sensitive than NMR, detecting metabolites at significantly lower concentrations (nanomolar versus micromolar concentrations) (10). Complex mixtures such as urine, plasma, or, in this study, extracellular medium from cells are initially separated by liquid chromatography (LC). Mass spectrometry is performed following LC separation to detect the spectra of small molecules present in biological samples. In this study, we specifically employ electrospray ionization time of flight mass spectrometry (ESI-TOF-MS), which provides highly accurate measurements of the exact mass of small molecules with resolution of $3 \mathrm{ppm}$ (11). Small molecules such as sugars, organic acids, amino acids and fatty acids participate in functional mechanisms of cellular response to pathological or chemical insult. As a result, these small molecules may serve as candidate biomarkers of disease or toxic response and can be detected in biological fluids (12).

Abnormal production of metabolites following exposure to pharmaceuticals, dietary deficiencies, or disease may provide a mechanistic insight into these processes. For example, the small molecule $N$-acetylaspartate (NAA), a neuronal marker, is significantly reduced in motor cortex and corticospinal-tract (CST) brain regions of amyothrophic lateral sclerosis (ALS) patients $(13,14)$. The decrease in NAA is associated with neuronal loss in specific brain regions affected by the disease. NAA decrease correlated to clinical indicators of upper motor neuron dysfunction in ALS patients (ALS Functional Rating Scale-Revised, finger and foot tapping, strength testing), suggesting that this small molecule metabolite is related to disease mechanisms $(13,14)$. Metabolomics identifies actual metabolites and biochemical pathways that are disturbed in response to an insult rather than a prediction of what could happen. Thus, metabolomics offers a more functional insight into the onset of cellular disorders in comparison to that provided by genomics.

Antiepileptic exposure during the first trimester of pregnancy causes functional damage to the developing embryo and fetus. Exposure to antiepileptic drugs (AED) in utero occurs in 1 of every 250 newborns (15). Valproate is the most teratogenic but widely adopted antiepileptic. Valproate impairs neuropsychological development as documented in multiple population studies $(16,17)$. Valproate exposure in utero during very early development increases the occurrence of spina bifida and neural tube defects (NTDs) in newborns (18) by $10-20$ times (for review, see ref. 19) and underlies cases of autism and cognitive dysfunction (20-22). The basis for the exquisite sensitivity of the early embryo and developing neural tube to AED-induced damage is incompletely understood.

Neurodevelopment is recapitulated in a reproducible and faithful manner by differentiation of hES cells $(4,5)$. The neural tube is composed of neuroepithelial, nestin positive neural precursors (NPs) (23), which proliferate, migrate, and differentiate into neurons, astrocytes, and glia. The duration of neuronal and glial differentiation from hES cells-NPs is similar to lineage allocation in vivo (for review, see ref. 24). Thus, detection of small molecules in hES cells and hNPs should indicate potential biochemical mechanisms of AED injury in early human development. These small molecules may predict detrimental effects of novel drugs. Unfortunately, current animal models can only predict human developmental toxicity with $\sim 50 \%$ accuracy ( 25 ).

Ideally, an understanding of these underlying mechanisms could improve our ability to prevent or repair this damage. Such knowledge might also translate into biomarkers and diagnostic tools to screen for and identify pregnant women at risk and/or their affected offspring. It is often difficult to confirm a suspected neurodevelopmental disorder other than spina bifida (26), and thus biomarker screens would open access to support services and essential care to improve outcome. A gestational screen might also help to identify and therefore focus treatment interventions on women at high risk for delivery of children with mental disabilities.

This study demonstrates proof of concept for metabolomics as a means to identify small molecules from hES cells and derivative cells from hES cells, such as NPs. A subset of small molecules in the metabolome of three different hES cell lines (H1, H9, and Cy203) and hNPs was significantly altered following exposure to valproate. These small molecules, secreted by undifferentiated hES cells and hNPs, may serve as candidate biomarkers for preclinical safety screening of pharmaceutical compounds or in vivo diagnostics in biofluids. Because small molecule metabolites participate in defined metabolic networks, metabolomics of hES cells and hNPs also revealed biochemical pathways (9) that may be sensitive to developmental disruptors and participate on the ontogenesis of birth defects.

\section{MATERIALS AND METHODS}

\section{Culture of hES cells}

H1 hES cells (passages 41-46) treated with $22 \mu \mathrm{M}$ of valproate and controls were cultured on six-well plates on Matrigel (BD Scientific) in the absence of feeders. $\mathrm{hES}$ cells were maintained in conditioned medium (CM) collected from mouse embryonic fibroblasts (MEFs) 


\section{METABOLOMICS IDENTIFICATION OF hES CELLS SMALL MOLECULES}

[80\% Dulbecco's modified Eagle medium (DMEM)/F12, Invitrogen, and $20 \%$ KNOCKOUT serum replacement, Invitrogen] supplemented with $1 \mathrm{mM}$ L-glutamine (Invitrogen), 1\% MEM nonessential amino acids (Invitrogen), and $0.1 \mathrm{mM}$ 2-mercaptoethanol (Sigma). The medium was supplemented with $4 \mathrm{ng} / \mathrm{ml}$ human recombinant basic fibroblast growth factor (hrFGF; Invitrogen). hES cells were passaged at $\sim 80 \%$ confluency, following incubation in $2 \mathrm{mg} / \mathrm{ml}$ dispase (Invitrogen) in DMEM/ F12 for $10 \mathrm{~min}$ at $37^{\circ} \mathrm{C}$. $\mathrm{H} 1$ and $\mathrm{H} 9 \mathrm{hES}$ cells (passages 33-34, 56-57, and 58-59) and Cy203 hES cells (Cythera Inc.) treated with $1 \mathrm{mM}$ valproate and controls were cultured under standard conditions described elsewhere (27, 28 respectively) .

\section{Differentiation of hES cells}

To differentiate Cy203 hES cells into hNP cells, colonies were manually isolated from MEFs and cut in small pieces, which were then transferred to a T75 flask with hES cell differentiation medium (standard culture medium described above for $\mathrm{H} 1 \mathrm{hES}$ cells with $10 \% \mathrm{KSR}$ and no FGF-2). Medium was replaced the following day by transferring the floating hES cells aggregates to a new flask. After culturing for a week, the hES cell aggregates formed mature embryoid bodies (EBs; $\sim 10 \mu \mathrm{m}$ round clusters with dark centers). EBs were plated on a polyornithine/laminin-coated $10-\mathrm{cm}$ dish in hES cell differentiation medium. The next day, the medium was changed to DMEM/F12 supplemented with $1 \times$ ITS and $500 \mu \mathrm{g} / \mathrm{ml}$ fibronectin. Medium was changed every other day for a week or until the cells formed rosette-like columnar structures that were isolated manually (Color Plate 1). These structures were then transferred to coated dishes in neural induction medium (DMEM/F12 supplemented with N2 and FGF-2) for 1 week. Elongated single cells were separated from leftover aggregates using nonenzymatic dissociation. After one to two passages, the cells formed a monolayer of homogeneous hNPs (positive for nestin, negative for Sox-1 immunostaining; Color Plate 1). Upon confluence, cells will form neurospheres that can also be isolated from the neuroepithelial precursor cells (positive for Sox-1 immunostaining). At any of these two stages, panneuronal differentiation can be achieved after 3-4 weeks following withdrawal of FGF-2.

\section{Treatment of hES cells with valproate}

The activity range of valproate, as determined by human enzymatic assays, varies from 10 to $10,000 \mu \mathrm{M}$ (29). Therapeutic doses and serum circulating levels for antiepileptic activity in patients are generally achieved at $1 \mathrm{mM}$ (30). The present study examined if significant changes in hES cell-derived small molecule metabolites could be detected following exposure to low and high doses of valproate. Three treatment regimens were performed for differential metabolomics: $\mathrm{H} 1 \mathrm{hES}$ cells were treated for $24 \mathrm{~h}$ with $22 \mu \mathrm{M}$ valproate (Sigma \#P4543) followed by collection of supernatant and cell pellets. In the second treatment group (4 days), H1 hES cells were exposed to valproate for 4 days, and supernatant and cell pellets were harvested on day 4 . In the third treatment, or extended culture, (EC, 8 days), H1 hES cells received valproate for 4 days followed by culture in standard hES cells medium for an additional 4 days. Cells and supernatant were harvested on day 8. Each treatment had a parallel untreated control group. The same treatment regimen was performed on $\mathrm{H} 1, \mathrm{H} 9$, and Cy203 hES cells using a higher dose of valproate $(1 \mathrm{mM})$, followed by harvesting of cells and supernatant at $24 \mathrm{~h}, 4$ days, and 8 days. hNPs differentiated from Cy203 hES cells (Color Plate 1) were treated with $1 \mathrm{mM}$ valproate for 4 days beginning on day 21 according to same procedures described above.

\section{Liquid chromatography and electrospray ionization time-of-flight mass spectrometry}

The supernatant from treated and untreated hES cells at the three time points ( $24 \mathrm{~h}, 4$ days, and 8 days) as well as aliquots of conditioned medium used in each experiment were stored at $-80^{\circ} \mathrm{C}$ until preparation for MS analysis. Samples were quenched in $20 \%$ acetonitrile and centrifuged through a Millipore 3-kDa Centricon column (Millipore) for $3 \mathrm{~h}$ at $4575 \times g$ to remove proteins and large-molecular-weight $(>3-\mathrm{kDa})$ biomolecules. The flowthrough was retained for analysis because it contains the small molecules free of high-molecular-weight compounds. Each sample had three replicates injected into a $2.1 \times 200-m m$ C18 column run on a 90-min gradient from $5 \%$ acetonitrile, $95 \%$ water, $0.1 \%$ formic acid to $100 \%$ acetonitrile, $0.1 \%$ formic acid at a flow rate of $40-80 \mu \mathrm{l} / \mathrm{min}$. The flowthrough was introduced into an Agilent 1100 series ESI-TOF, which has a dual electrospray ionization source and lock spray for better than 3 ppm mass accuracy. Data was collected from 50-1,500 $\mathrm{m} / \mathrm{z}$ range throughout the run. The raw data were loaded into the Mass Hunter program (Agilent) to show retention time and neutral accurate mass features.

\section{MS data analysis}

The Mass Hunter (Agilent) software was applied to deconvolute the data and determine the abundance of each mass. Data was extracted from the entire mass spectra using the $m / z$ range of $0-1,500$ and the top 2-5 million most abundant mass peaks from each sample were used for data deconvolution. The minimum signal-to-noise ratio was set to 5 . The masses with a minimum relative abundance greater than $0.1 \%$ were exported from the Mass Hunter software and used for further analysis. 


\section{CEZAR ET AL.}

A mass was considered to be the same across LC/ESITOF-MS runs using a simple algorithm that first sorts the data by mass and retention time. After sorting, a set of mass features was considered a unique bin or putative small molecule if it had a retention time difference of less than or equal to $3 \mathrm{~min}$ and a mass difference less than or equal this weighted formula $(0.000011 \times$ mass $)$. The criteria used for the $1 \mathrm{mM}$ valproate-treated hES cells and hNPs was based on a sliding mass scale to compensate for detector efficiency. Because the flow rate increased from $40 \mu \mathrm{l}$ in $22 \mu \mathrm{M}$ to $80 \mu \mathrm{l}$ in $1 \mathrm{mM}$ experiments, a mass was considered equivalent if it was within $(0.00001 \times$ mass $)$ when under $175 \mathrm{Da},(0.000007 \times$ mass) when $176 \mathrm{Da}-300 \mathrm{Da}$, and $(0.000005 \times$ mass $)$ when over 300 Da with a retention time difference of 1.5 min. If a series of measurements fits this definition, it is considered to be from the same compound within each experiment. If either the mass or the retention time vary by more than the limits listed above, the compound is considered to be a different one and given a different bin description.

Significance was determined by analysis of variance (ANOVA) on the log base 2-transformed abundance values of unique compounds present in treated and untreated medium at each time point. A randomized complete block design was used with the following formula $\log _{2}\left(\right.$ abundance $\left._{t b}\right)=$ treatment $_{t}+$ experiment $_{b}+$ error $_{t b}$, where treatment corresponds to valproate-treated or untreated cells and experiment corresponds to complete experimental blocks. The residual error was used as the error term in the ANOVA model. Missing data were omitted from the test, changing the degrees of freedom rather than performing missing data inputation. This assumption was made because of the extensive filtering performed by the Mass Hunter software which may miss or filter certain peaks because they are below a certain abundance threshold and not zero. The ANOVA F-test was considered significant if its $p$ value was less than 0.05 . Fold changes were calculated using the least squares means for a given time and treatment.

\section{Immunohistochemistry}

hES cells were fixed in $4 \%$ paraformaldehyde in phosphate-buffered saline (PBS) for $15 \mathrm{~min}$ at $25^{\circ} \mathrm{C}$. The cells were washed twice for 5 min with KPBS-T and incubated in KPBS-T for 30 min prior to blocking. The cells were blocked for $1 \mathrm{~h}$ at $25^{\circ} \mathrm{C}$ with $1 \times$ Sigma (\#B6429) Blocking Buffer diluted in KPBS-T. The cells were then incubated with Oct-3/4 (C-10, Santa Cruz mouse monoclonal antibody sc-5279) overnight at $4^{\circ} \mathrm{C}$ at a $1: 100$ dilution $(2 \mu \mathrm{g} / \mathrm{ml})$ in KPBS-T. Santa Cruz immunoglobulin $\mathrm{G}_{2 \mathrm{~b}}$ $\left(\mathrm{IgG}_{2 \mathrm{~b}}\right.$; sc-3879) was used as a negative control, under the same conditions. After incubation the cells were washed three times with KPBS-T for 5 min at $25^{\circ} \mathrm{C}$. The rabbit anti-mouse fluorophore Alexa Flour 488 (A11059, Molecular Probes) was then added to cell preparations at 1:1,000 $(2 \mu \mathrm{g} / \mathrm{ml})$ dilution in KPBS-T for $1 \mathrm{~h}$ at $25^{\circ} \mathrm{C}$, followed by three washes with KPBS-T for 5 min each. Immunohistochemistry (IHC) for hNP was performed on day 21 with 1:100 antibodies for nestin (Chemicon), as described in previous studies (28).

\section{Annotation and identification of small molecules}

The neutral exact mass and/or empirical chemical formula of each compound, detected by ESI-TOF MS, was queried in public searchable databases, METLIN (http:// metlin.scripps.edu), The Human Metabolome Database (http://www.hmdb.ca), Kyoto Encyclopedia of Genes and Genomes (www.genome.jp/kegg/), and the Biological Magnetic Resonance Bank (http://www.bmrb.wisc.edu/ metabolomics/) for candidate identities. LC-MS-measured mass signals matched small molecules present in the databases if their exact masses were within 10 parts per million $(0.00001 \times$ mass $)$. Exact mass measurements and chemical formulae are generally nonambiguous for molecules up to $300 \mathrm{Da}$, whereas larger molecules may have several elemental formulae (31). Analytical-grade chemical standards were purchased from Sigma for comparative MS. Aliquots of conditioned medium used in experiments were spiked with $1 \mathrm{mM}$ chemical standards followed by standard LC/ESI-TOF MS, as described above. The neutral exact masses and retention times for standard compounds in spiked conditioned medium were used to re-extract peaks in experimental samples (hES cell supernatant) using the Analyst software (Agilent).

\section{$R T-P C R$}

$\mathrm{H} 1 \mathrm{hES}$ cells treated with $1 \mathrm{mM}$ valproate and untreated controls were harvested at 4 days after treatment and stored at $-80^{\circ} \mathrm{C}$ prior to RNA isolation using RNeasy (Qiagen). Total RNA (3.5 $\mu \mathrm{g})$ was DNase treated (Promega) for $20 \mathrm{~min}$ at $37^{\circ} \mathrm{C}$. The cDNA was primed with Oligo(dT) $)_{15}$ (Promega). Reverse transcription was carried out using $1 \times$ Moloney murine leukemia virus (MMLV) reaction buffer, $0.5 \mathrm{mM}$ dNTPs (Promega), 400 IU M-MLV reverse transcriptase (Promega), and $20 \mathrm{IU}$ RNasin (Promega). The reaction was incubated at $42^{\circ} \mathrm{C}$ for $2 \mathrm{~h}$ and heated to $70^{\circ} \mathrm{C}$ for $10 \mathrm{~min}$ to stop the reaction. Negative control reactions were created under the same conditions, except that the reverse transcriptase was omitted. PCR was performed on $2 \mu$ l of cDNA using $1 \times$ Qiagen Hot Start master mix with the following cycling parametes: $95^{\circ} \mathrm{C} 15 \mathrm{~min}$, followed by 34 cycles of $\left(94^{\circ} \mathrm{C}, 30 \mathrm{~s}, 56^{\circ} \mathrm{C}, 30 \mathrm{~s}, 72^{\circ} \mathrm{C}, 45 \mathrm{~s}\right)$ and a final step of $72^{\circ} \mathrm{C}$ for $7 \mathrm{~min}$. The primers used for each gene/ accession numbers were: INDO, indoleamine 2,3-dioxygenase, NM_002164 (forward TCTGGCCAGCTTC- 

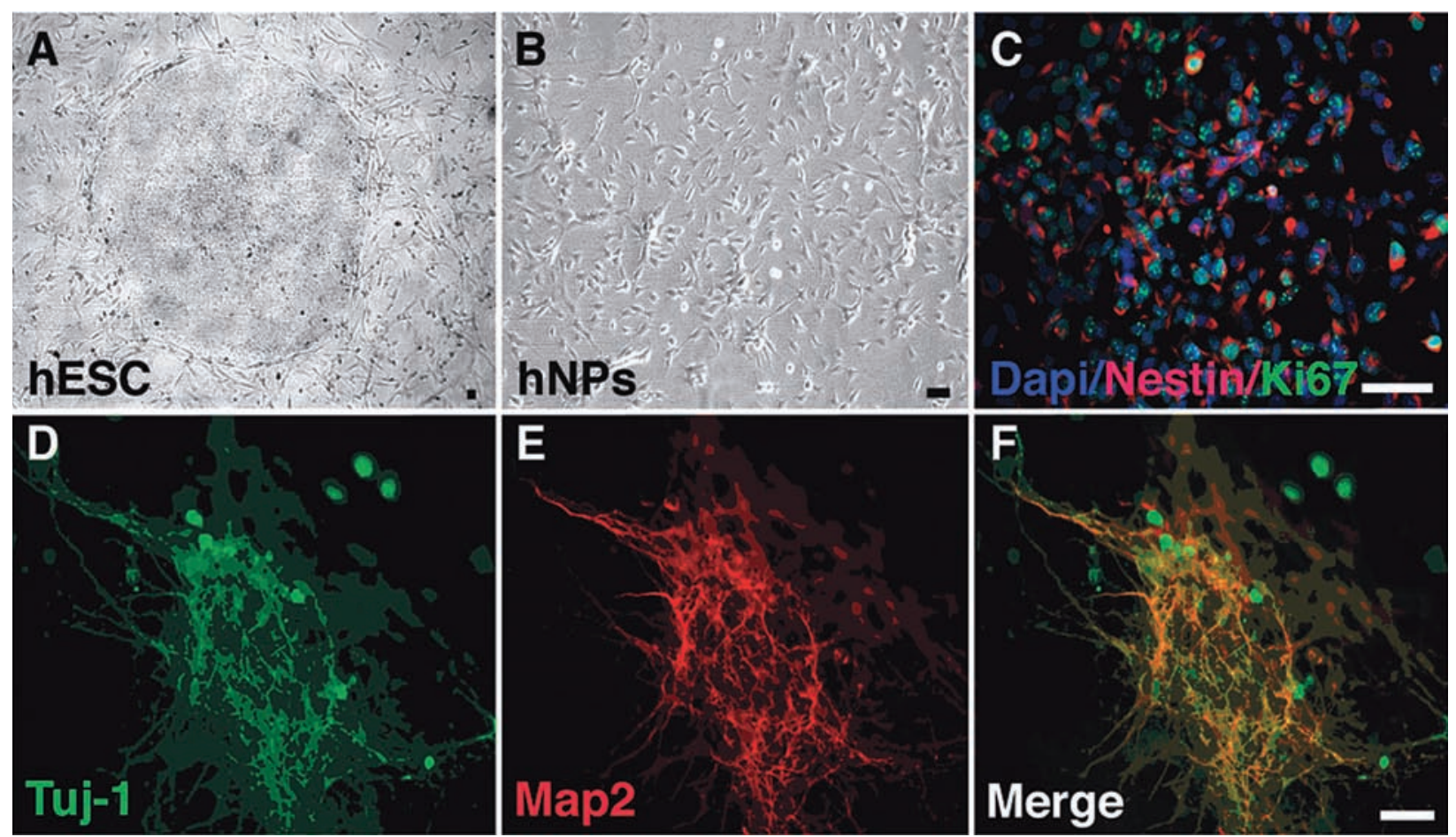

COLOR PLATE 1. Derivation of hNPs from hES cells. (A) Aspect of an undifferentiated hES cells colony growing in the presence of MEFs. (B) Expansion of hNPs after derivation (see Materials and Methods). (C) hNPs are a homogenous population of nestin-expressing cells. Most of the cells also express the cell cycle marker Ki67. hNPs can be differentiated into neurons (D, Tuj-1 positive; E, Map2 positive) upon withdrawal of FGF-2. Bar, $15 \mu \mathrm{m}$. (F) Tuj-1 and Map2 merged.

GAGAAAGAGTT, reverse AGGAGGCAGTTCCAGTTTCTTGGA); TDO2, tryptophan 2,3-dioxygenase, NM_005651 (forward ACTCCAGGTTTAGAGCCACATGGA, reverse TCAATGCTCCCTGAAGTGCTCTGT); AFMID, arylformamidase, NM_001010982 (for- ward TGTGCTGGTGGTCGTGGAG, reverse CACGTTGTCCTTCTGGGTCAGATT); TPH1, tryptophan hydroxylase, NM_004179 (forward AGCCCTTTGATCCCAAGATTACCTGC, reverse GCAGCTCATTCATGGCACTGGTTA); AADAT, aminoadipate aminotrans-
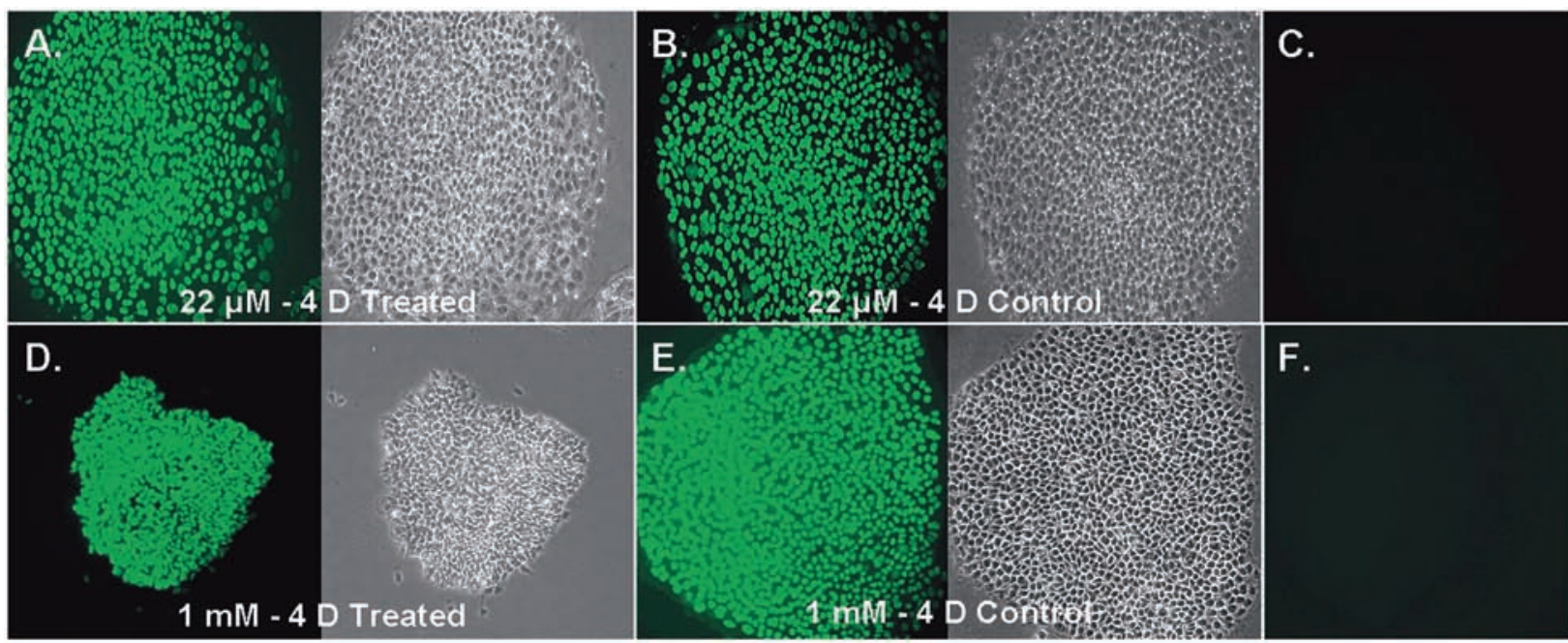

F.

COLOR PLATE 2. Immunohistochemistry of Oct-4 at day 4 in H1 hES cells treated with $22 \mu \mathrm{M}(\mathbf{A})$ and controls (B) and $1 \mathrm{mM}$ valproate (D) in comparison to controls $(\mathbf{E})$. $(\mathbf{C}, \mathbf{F})$ Negative controls without addition of antibodies. Expression of Oct4, a marker of pluripotency, was sustained following treatment with low and high doses of valproate. 
ferase, NM_016228 (forward GGTTTGGCAGAATGGCATGTTCTT, reverse TGTGCTAATACCTGGAAGGCCACA); KYNU, kynureninase, NM_001032998 (forward AGCTGGACAAGCGAAGGGTTGTTA, reverse TGAGTTCATGGCCAAACCATCCCA); KMO, kynurenine 3-monooxygenase, NM_003679 (forward ATGCGAGCACATGTCAACTCAAGC, reverse AGTAGGTAGGTACTGCTGATGGCT); and GAPDH, glyceraldehyde 3-phosphate dehydrogenase, NC_000012 (forward ACAGTCAGCCGCATCTTCTT, reverse GACAAGCTTCCCGTTCTCAG).

\section{RESULTS}

\section{The pluripotency hES cells marker Oct-4 remained in hES cells treated with valproate}

hES cells are highly sensitive to the culture microenvironment (1), which challenges their application in cellbased assays for pharmaceutical screening. H1, H9, and Cy203 hES cells remained pluripotent for multiple passages following 4 days of treatment with low and high doses of valproate (22 $\mu \mathrm{M}-1 \mathrm{mM})$ (32-34). A concentration of $1 \mathrm{mM}$ is equivalent to the therapeutic range of valproate and serum circulating levels in treated patients (30). The pluripotency hES cell marker Oct-4 was retained in treated hES cells in a similar manner as untreated controls (Color Plate 2).

Secreted small molecules from hES cells and hNPs are measured by LC/ESI-TOF mass spectrometry

Our analysis detected an average of 3,000 mass features after data deconvolution per LC-MS run (132 individual runs). Complex mixtures were separated by LC prior to ESI-TOF-MS (35). Metabolic profiling was conducted on extracellular small molecules as opposed to intracellular compounds. Extracellular small molecules were analyzed because our future goal is to examine candidate biomarkers discovered in vitro in biofluids in vivo. Biofluids, such as serum, urine, and cerebrospinal fluid, contain a mixture of extracellular biomolecules. The analysis of intracellular metabolites for biomarker discovery is an alternative approach, but evaluation of these findings in a clinical setting requires more invasive procedures such as tissue biopsies.

Multiple metabolite peaks changed in response to valproate as early as $24 \mathrm{~h}$ as compared to untreated controls (Color Plate 3). In all, 3-5\% of compounds (22 $\mu \mathrm{M}$ and $1 \mathrm{mM}$ valproate, respectively) had statistically significant differences in at least one time point in treated hES cells. Changes as high as 37 fold were measured after valproate treatment, but the mass signals associated with these changes were not measured consistently across experiments.

The identity of several statistically significant metabolites, secreted by both hES cells and hNPs, remains to be determined. This finding is consistent with previous metabolomics studies (6), where $50 \%$ of the measured masses could not be annotated. The lack of comprehensive chemical databases of human metabolites is a major challenge to the relatively novel field of metabolomics. Public databases are available for bioinformatics queries based on exact chemical masses. Nonetheless, the vast majority of small molecules detected by LC/ESI-TOFMS are not yet catalogued. Therefore, metabolic profiling of hES cells should contribute to the discovery of new chemical compounds. Many metabolites from human development and disease are also likely present in conditioned medium from MEFs due to common metabolic pathways. Rigorous investigation is required to validate candidate biomarkers that are not exclusive to hES cells and are also present in the medium. This can be achieved by modulation of metabolic pathways with receptor ligands or enzyme inhibitors.

\section{Valproate induces significant changes in small molecules in the kynurenine and glutamate pathways in hES cells}

An alternative nonprotein tryptophan metabolic pathway, activated during pregnancy and immune response (36), produces an intermediate metabolite known as kynurenine. The levels of kynurenine increased by $44 \%$ ( $p=0.004$ at 4 days) following $22 \mu \mathrm{M}$ valproate treatment. Kynurenine was detected exclusively in hES cells and absent in conditioned medium. The chemical identity of this peak was confirmed by comparative mass spectrometry in the presence of the chemical standard (Fig. 1). Glutamate and pyroglutamic acid were also elevated in response to valproate $(20 \%$ and $27 \%$, respectively), although only pyroglutamic acid exhibited statistically significant changes ( $p=0.021$ at 4 days; Fig. 1). Glutathione, $S$-adenosyl-homocysteine, and Cys-Gly were detected at very low levels in comparison to other mass signals (data not shown). Small molecules were identified by comparative mass spectra and retention times with conditioned medium spiked with chemical standards at different concentrations (Fig. 1). We also hypothesized that metabolites in folate and related pathways (37) would change in response to valproate. Folic acid was significantly increased by $16 \%$ in the extracellular medium of hES cells treated with valproate $(p=0.022$ at 8 days; Fig. 1) but not its derivative dihydrofolate. Mammalian cells do not synthesize folic acid, therefore future studies will examine whether valproate interferes with the cellular uptake of folic acid.

Alterations in the kynurenine and glutamate pathways 

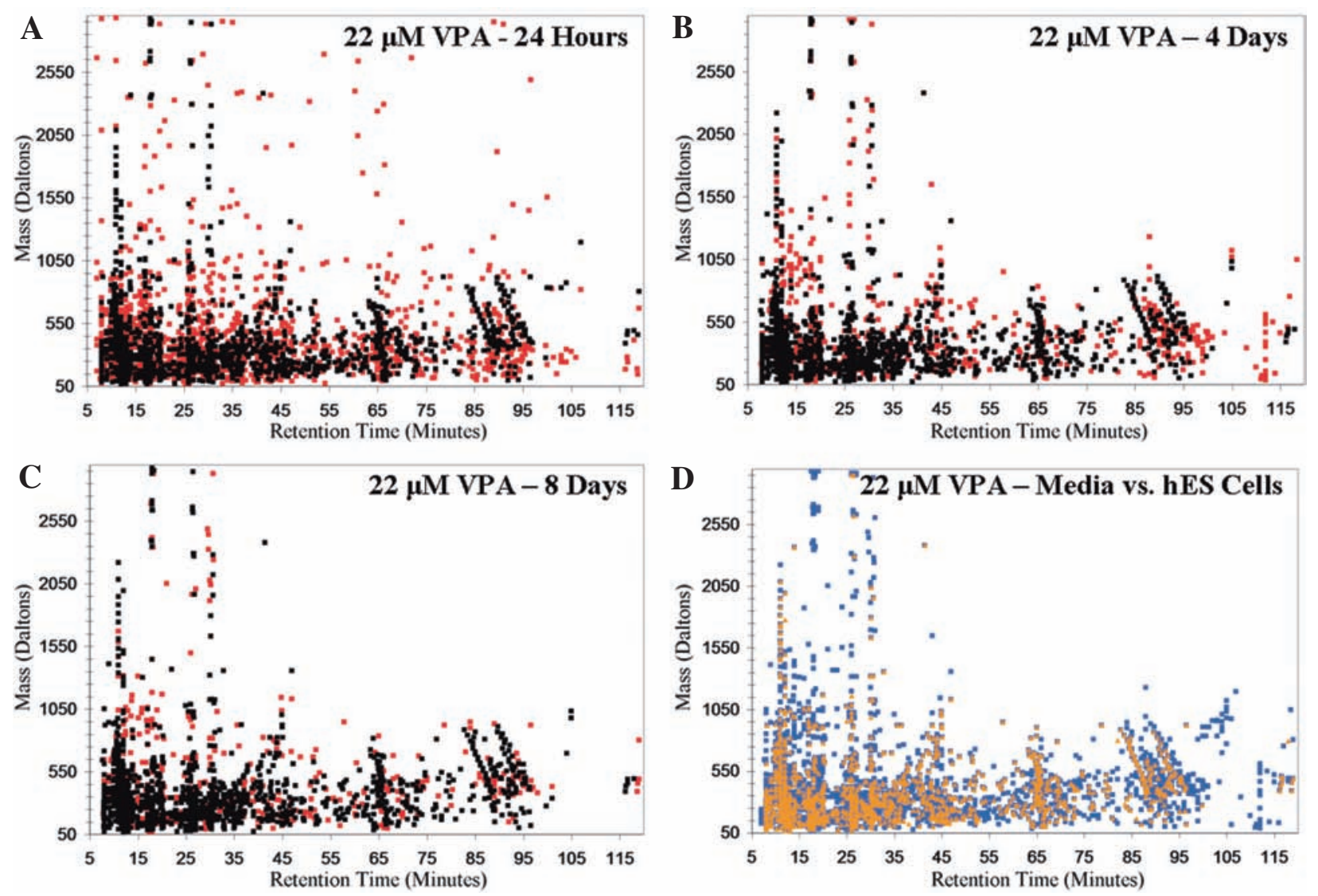

COLOR PLATE 3. Metabolic profiling (mass versus retention time) of small molecules detected by ESI-TOF MS at different time points (A-C) in valproate (VPA)-treated hES cells (red) and untreated controls (black). Most mass signals were up-regulated at 4 days after treatment in comparison to $24 \mathrm{~h}$ and 8 days (C). (D) Comparative metabolic profiling of hES cells (blue) and conditioned medium (yellow).

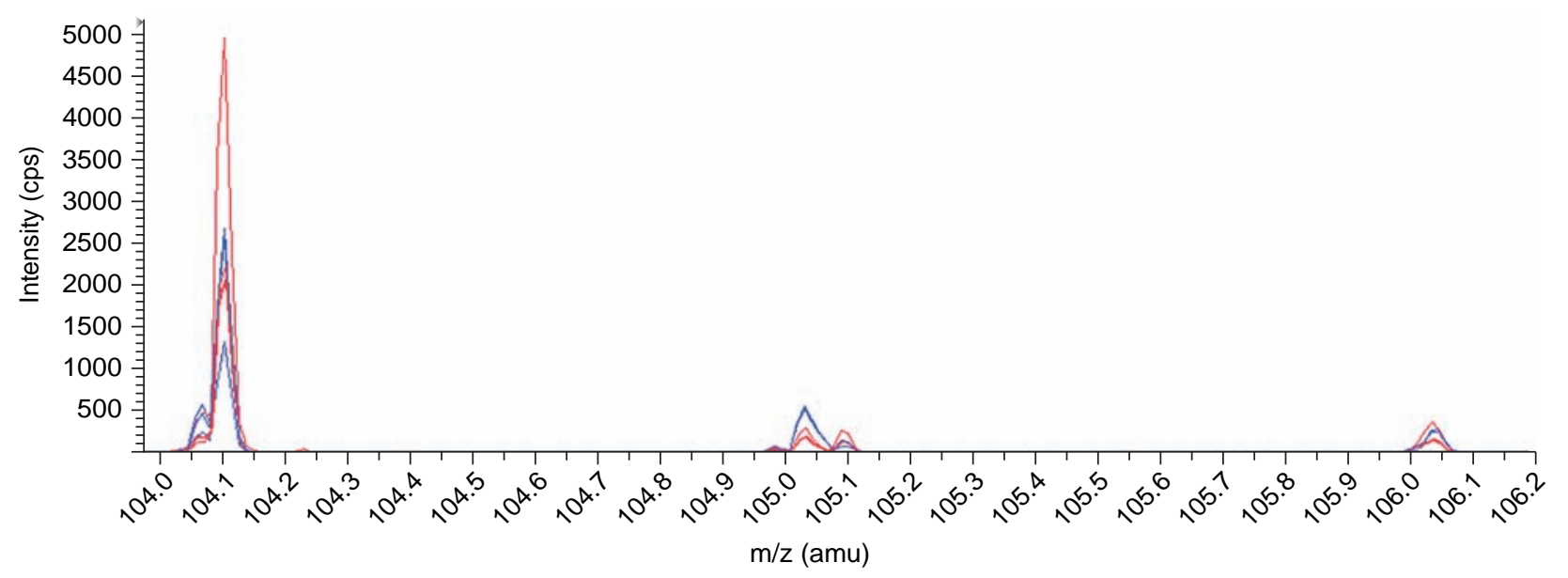

COLOR PLATE 4. Ion traces of putative metabolite of GABA (exact mass 103.0633 ) after deconvolution in three biological replications shows increased abundance in hES cells treated with $1 \mathrm{mM}$ valproate (red) in comparison to untreated controls (blue). 

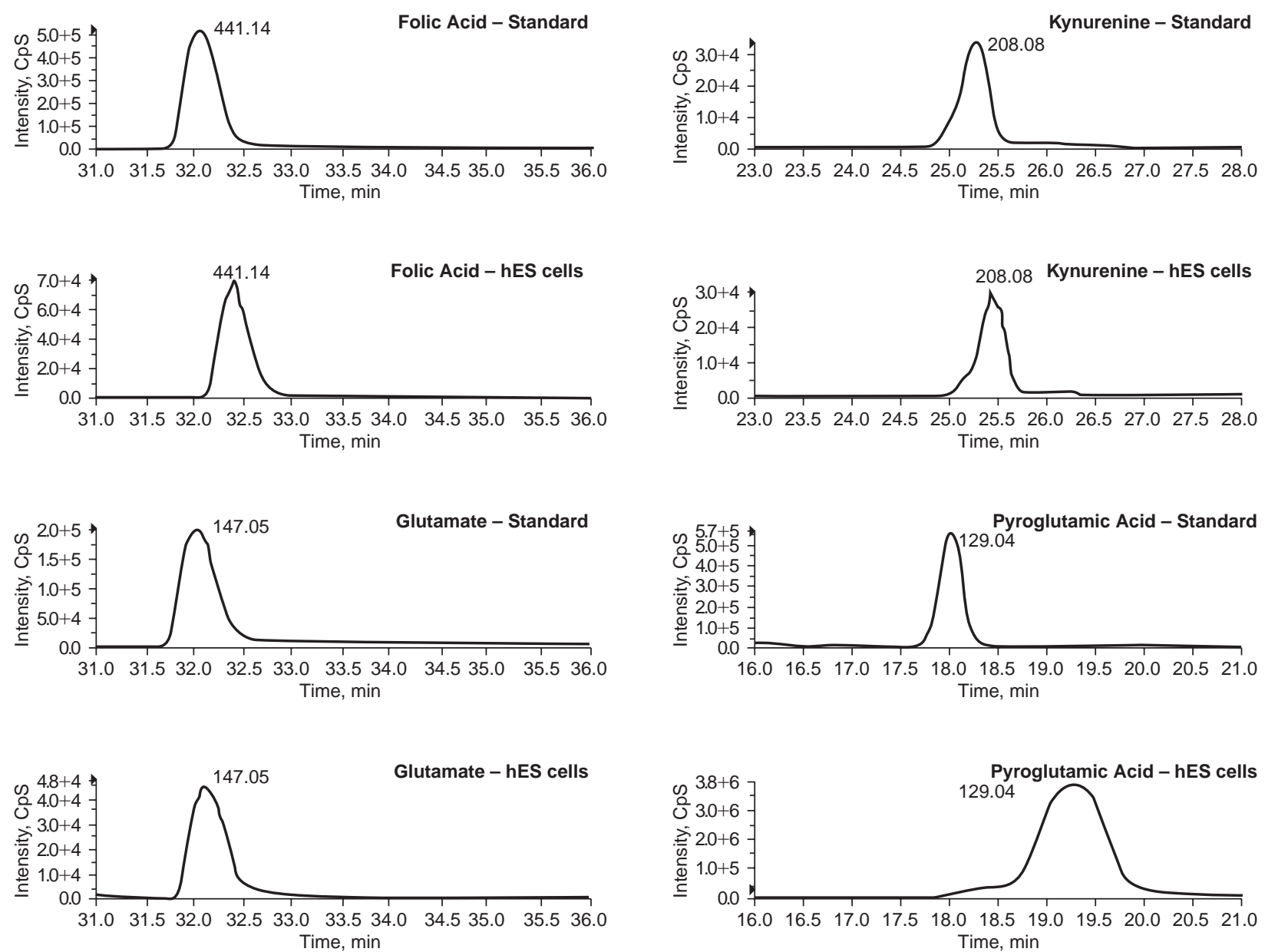

FIG. 1. Comparative MS integration peaks (abundance versus retention time) of conditioned medium spiked with chemical standards (upper panels) and experimental samples (bottom panels). Integration peaks were obtained for each exact mass to confirm the chemical identity of compounds. Fluctuations in the retention times were within 1-min thresholds between spiked and experimental samples.

were consistent in hES cells treated with $1 \mathrm{mM}$ valproate), where a 16-fold upregulation of pyroglutamic acid was observed $(p=0.01)$ along with marked changes in other putative metabolites in the kynurenine pathway, such as kynurenic acid (exact mass 189.0426, $p=$ 0.02 ), and formylkynurenine (exact mass 236.0794, $p=$ 0.0003 ) in comparison to untreated controls. A putative metabolite is a small molecule whose exact mass, identified under our conditions, matched exact mass measurements and equivalent elemental formulas from databases. Positive fold changes $(>2)$ in putative metabolites in kynurenine and glutamate pathways were verified in another hES cell line, Cy 203, and in nestin-positive hNPs derived from these cells. These additional experiments suggest that significant changes detected by metabolomics can be reproduced in other hES cell lines. Continued experimentation will allow inferences regarding the statistical significance of the observed fold changes for the Cy203 hES cell line.
Treatment of hES cells and hNPs with $1 \mathrm{mM}$ valproate (Color Plate 5) significantly affected another pathway in comparison to $22 \mu \mathrm{M}$ : $\gamma$-aminobutyric acid (GABA) (Color Plate 4). GABA is synthesized from glutamate as a result of L-glutamic acid decarboxylase activity. GABA signaling is a well-known, established target of antiepileptics, and increases in extracellular concentrations of GABA have been reported upon fetal exposure to valproate $(33,38,39)$. Eight small molecules with identical accurate mass measurements and similar retention times to GABA metabolites were statistically significant in $\mathrm{hES}$ cells ( $p$ value $=0.0004-0.03$ ) treated with valproate, four of which were also upregulated in hNPs.

Treatment of hNPs with valproate induced fold changes in small molecules that were not detected in hES cells. A small molecule with a mass spectral match to citrulline (exact mass 217.1048), a urea cycle intermediate and byproduct of nitric oxide synthase, presented a 23fold increase at 4 days after treatment in hNP. We have 


\section{METABOLOMICS IDENTIFICATION OF HES CELLS SMALL MOLECULES}

A

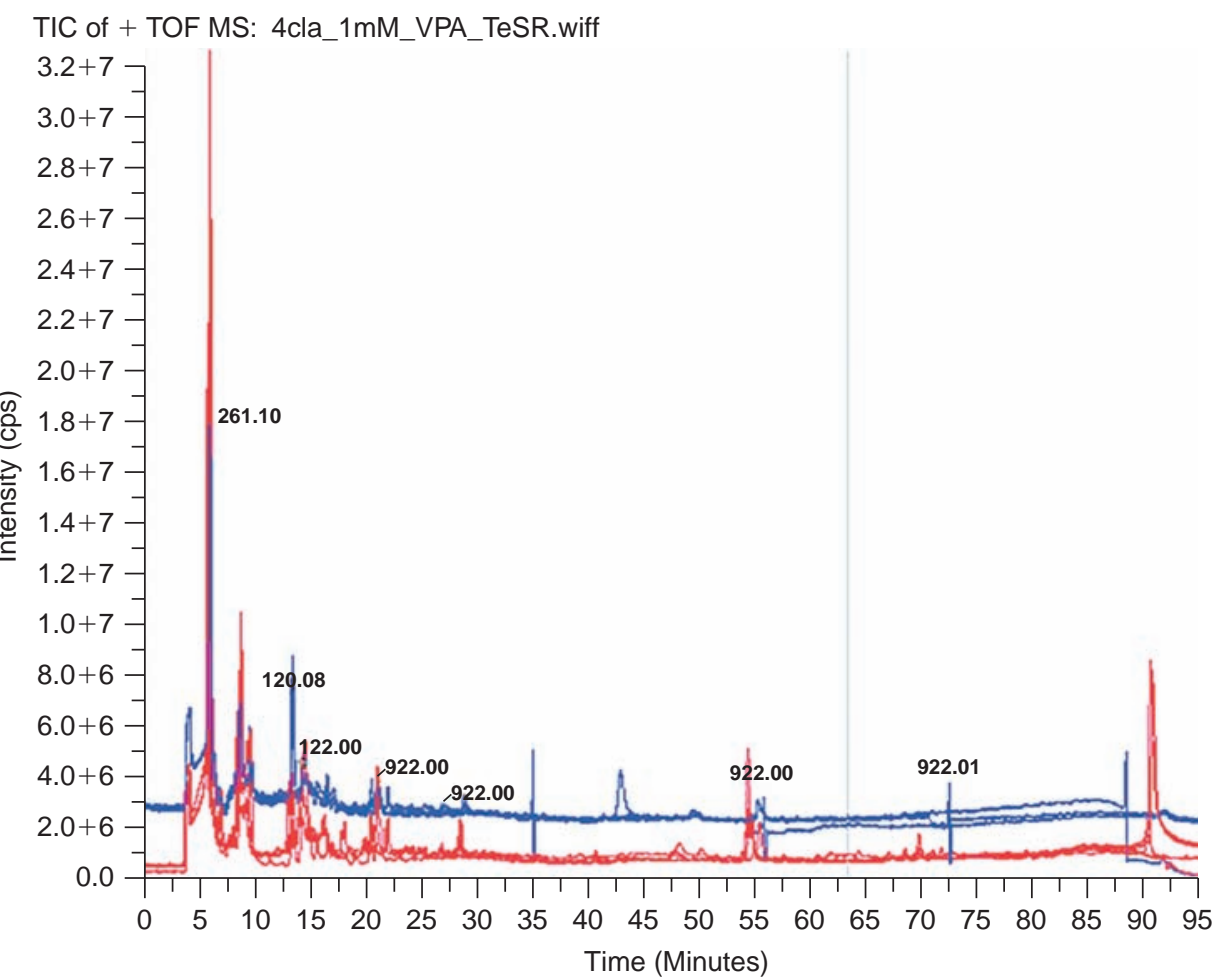

B

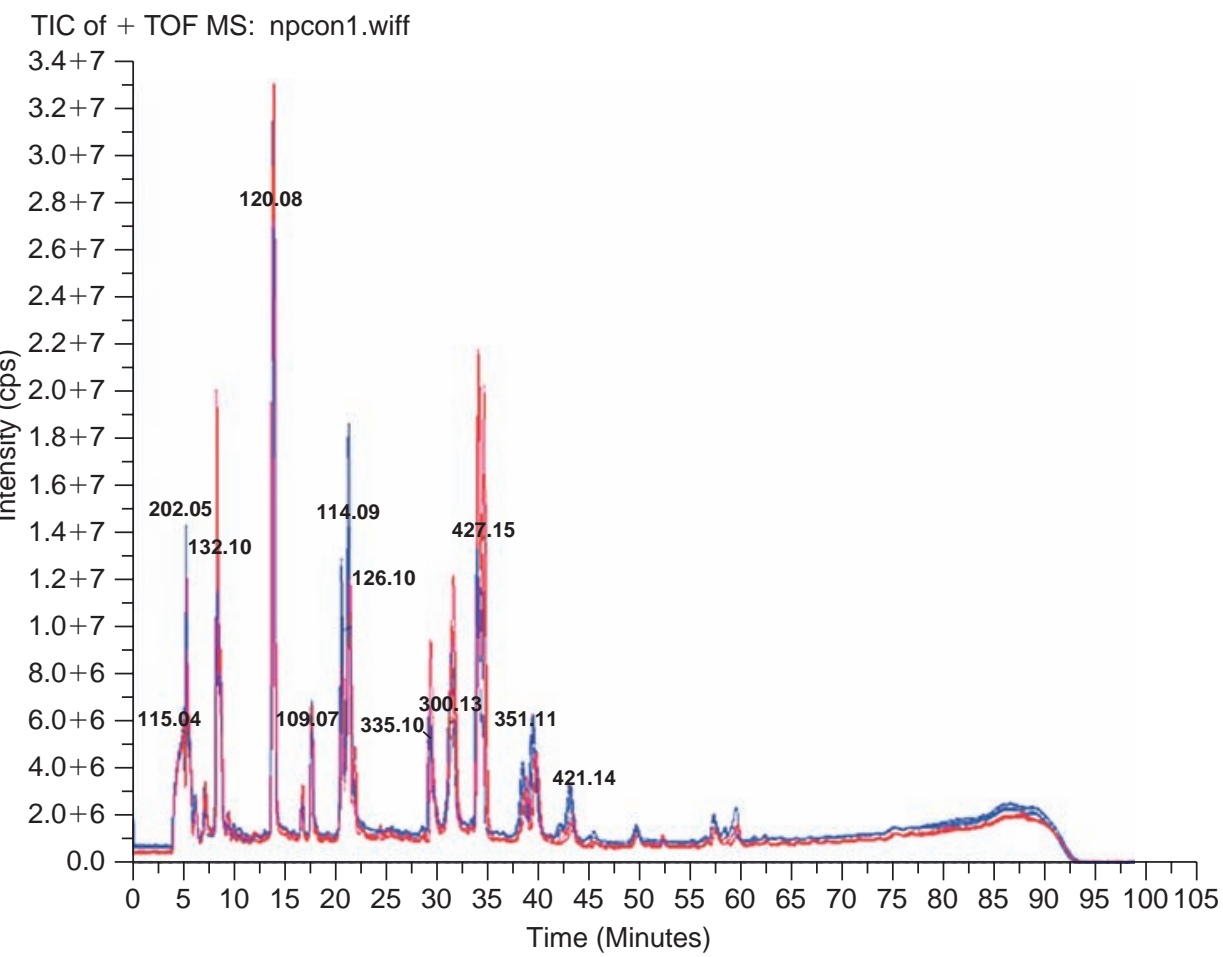

COLOR PLATE 5. Total ion chromatograms (TIC) or mass spectra of (red) hES cells (A) and hNPs (B) following treatment with $1 \mathrm{mM}$ valproate (red) in comparison to untreated controls (blue). 


\section{CEZAR ET AL.}

preliminary findings suggesting that some of the hNPspecific metabolites are putative serotonin metabolites. Future experiments will confirm if down-regulation of putative metabolites in serotonin synthesis (serotonin, exact mass 176.0946 and hydroxytryptophol, exact mass 177.0789 , among others) are statistically significant.

\section{Rate-limiting and key enzymes in the kynurenine} pathway are expressed in hES cells

Valproate treatment of hES cells induced a marked upregulation in the small molecule kynurenine, which is an intermediate metabolite in the catabolism of tryptophan. Tryptophan is the precursor of the neurotransmitter serotonin (5HT). Thus, we investigated if critical enzymes in the metabolism of tryptophan to kynurenine and its opposite route, serotonin synthesis, were expressed in hES cells. Our preliminary data show that the majority of critical enzymes in the kynurenine pathway and serotonin synthesis are expressed in hES cells at 4 days after treatment with $1 \mathrm{mM}$ valproate and in controls (Fig. 2). Indoleamine 2,3-dioxygenase (INDO), catabolizes tryptophan into the kynurenine pathway. INDO enzymatic activity produces kynurenine as an end product. The expression of tryptophan 2,3-dioxygenase (TDO or TDO2) was also examined. TDO2, like INDO, is capable of catalyzing the first step in the kynurenine pathway. Following multiple analysis of $\mathrm{H} 1 \mathrm{hES}$ cells treated with 1 $\mathrm{mM}$ valproate, our data suggest that TDO2 expression is up-regulated in hES cells treated with valproate in comparison to untreated controls (Fig. 2). An association between TDO2 and neurodevelopmental disorders, such as autism, has been proposed (40). The rate-limiting enzyme in 5HT synthesis, TPH1, is also expressed in hES cells (Fig. 2), and its expression is upregulated in valproatetreated hES cells in comparison to controls. The expression of these enzymes in hES cells and detection of specific effects of valproate on the transcription of key enzymes such as TDO2 and TPH1 is an initial finding to support the ability of hES cells to recapitulate metabolic pathways of tryptophan catabolism and serotonin synthesis.

\section{DISCUSSION}

The identification of small molecules metabolites in hES cells and hNPs enables the investigation of biochemical pathways and metabolic changes induced by valproate during early human development. Contrary to tissue injury in adults, the onset and progress of developmental disorders cannot be monitored clinically due to its development in utero. Importantly, "cognitive genes," which are likely perturbed by valproate (18-20), have such diverse neurodevelopmental roles (for review, see ref. 41) that establishment of pathways and networks involved in the genesis of neuropsychological disorders have been unsuccessful. Metabolomics of hES cells may be an alternative to current research approaches. Pathway elucidation using cells from human embryos (hES cells) provides unique information on human development because these cells are able to recapitulate differentiation into functional somatic cells.

The small molecule kynurenine was upregulated $44 \%$ in hES cells treated with $22 \mu \mathrm{M}$ of valproate. The kynurenine pathway has direct effects on the bioavailability of tryptophan. Tryptophan is the precursor of serotonin, a neurotransmitter that is altered in behavioral and cognitive disorders, which often result from in utero exposure to valproate (18-20). Serotonin participates in sensory perception, mood regulation, sleep-wake cycles, sexual arousal, and appetite, among others. Cognitive and behavioral disorders are known adverse effects of antiepileptic exposure during pregnancy $(16,17,21,42)$. Thus, we propose that kynurenine and its metabolites serve as a candidate biomarkers for developmental toxicity of AED. Strikingly, recent studies suggest that the kynurenine pathway may be a novel target for the mechanism of action of AED (43), which is the primary indication of valproate. It is well established that pharmacological targets may mediate therapeutic effects in adult cells and toxic effects in embryonic cells. On the basis of small molecules findings from the present study, we are currently testing the hypothesis in animal models that an increase in kynurenine during development may affect the bioavailability of tryptophan and, consequentl, serotonin, leading to neurodevelopmental disorders. Our ongoing studies will examine specific effects of valproate on the ability of hES cells to differentiate into neural tube precursors and functional 5HT neurons.

Glutamate and pyroglutamic acid, or hydroxyproline, were also elevated in hES cells and hNPs treated with valproate. Therefore, we suggest that valproate can affect the glutamate biochemical pathway in the developing human embryo. The affinity of AED for glutamate targets has been suggested previously (39). Disruption of the glutamate biochemical pathway in NTDs, another adverse side effect of valproate, was demonstrated upon analysis of maternal serum and amniotic fluid in spina bifida (8). The levels of glutamate and pyroglutamic acid were increased in NTDs (8); thus, the hES cell system may serve as a robust model to predict biochemical alterations during early development.

At therapeutic doses $(1 \mathrm{mM})$, valproate produced significant changes in candidate metabolites of GABA in hES cells as well as positive fold changes in hNPs. GABA is synthesized from glutamate, and the effect of valproate on GABA neurophysiology is a well-established mechanism of antiepileptic activity both in vitro and in vivo 


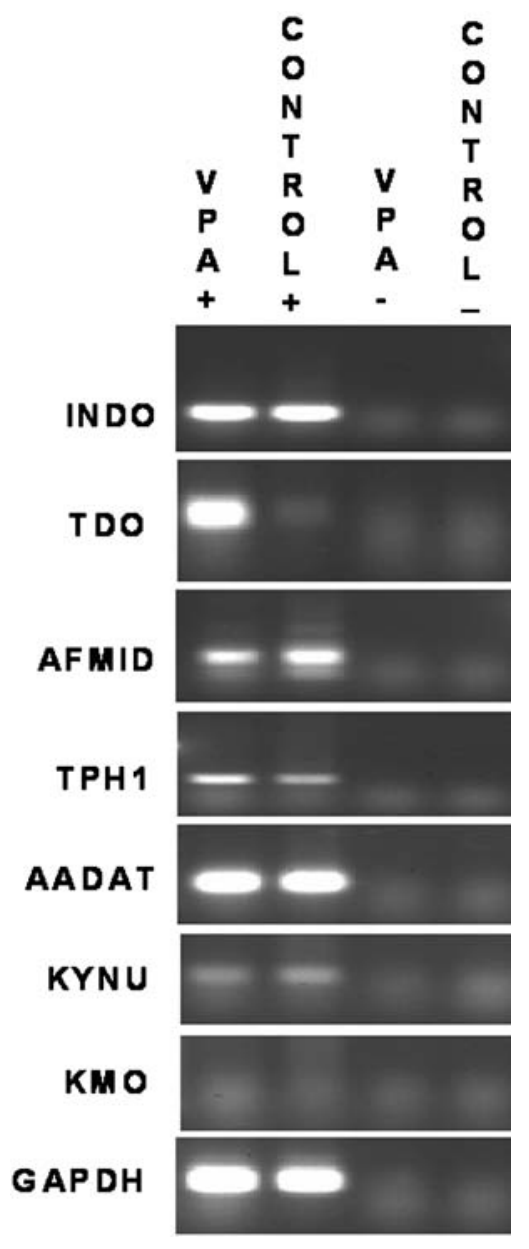

FIG. 2. Key and rate-limiting enzymes of the kynurenine and serotonin synthesis pathways are expressed in hES cells. TDO2 was up-regulated in valproate-treated $\mathrm{hES}$ cells in comparison to controls. AFMID, arylformamidase; TPH1, tryptophan hydroxylase; AADAT, aminoadipate aminotransferase; KYNU, kynunreninase; GAPDH, glyceraldehyde 3-phosphate dehydrogenase, housekeeping control gene. Kynurenine 3monooxygenase (KMO) was not expressed in valproate-treated cells or controls. Valproate-treated and untreated cells (VPA+ and Control+). VPA - and Control- are negative controls (no cDNA).

$(33,38,39)$. However, the fact that low doses of valproate were sufficient to produce significant changes in metabolite profiles suggests that early human embryonic cells may be highly sensitive to AED in comparison to differentiated somatic cells, which are often used to predict developmental toxicity (for review, see refs. 19 and 39).

Altogether, the metabolite changes detected in hES cells and hNPs in response to valproate converge functionally toward kynurenine and glutamate pathways. Our findings are in agreement with in vivo studies in rodents, where increased brain levels of glutamate and serotonin metabolites were detected after valproate treatment (44). Metabolites from the kynurenine path- way modulate activity at $N$-methyl-D-aspartic acid (NMDA) glutamate receptors (45). NMDA receptors and its ligand, glutamate, have a critical role in synaptogenesis in the developing brain (46). Perturbation of the physiology of these metabolic networks by developmental disruptors such as valproate, as suggested here, is a candidate mechanism for structural (NTDs) or functional (cognitive) disorders. Of particular interest is the finding that a small molecule with a mass spectral match to citrulline, a urea metabolite and byproduct of the enzyme nitric oxide synthase (NOS), was specifically upregulated in hNP by 23 fold. Although there are no reports on the specific association of citrulline to neural tube defects, its rate-limiting enzyme, NOS, is essential for neural tube closure (47). It is possible that citrulline may serve as a candidate biomarker of valproate injury specific to the developing human neural tube upon further investigation.

It remains to be determined whether exposure to valproate alters the ability of $\mathrm{hES}$ cells to differentiate into neuroepithelial precursors $(5,28)$ to model NTDs in vitro. We tested the hypothesis that exposure of hES cells to the developmental disrupter valproate induces significant differences in small-molecule metabolites, which can be measured by metabolomics. Small molecules from hES cells and derivatives are a novel target to elucidate how teratogens, such as valproate, may mediate injury during early human development. Perturbation of ES cell differentiation was not employed as an end point in the present study to assess the embryotoxicity of valproate, as in other comparable studies in the mouse $(48,34,49)$.

The outcomes of valproate on ES cell differentiation are controversial. Valproate inhibits neuronal maturation from ES cell-derived neuronal progenitors (34). In another study, similar doses of valproate impaired the expression of mesodermal and endodermal-inducing genes while increasing the expression of synaptophysin (Syn), a neural marker (48). Despite the fact that we did not specifically focus on effects of valproate on hES cells differentiation, some of our findings are in agreement with Murabe et al. (48). For example, in both our studies, Oct-4 was detected in a high percentage of undifferentiated cells (measured here by IHC as opposed to RTPCR) after treatment with a high concentration (0.70-1 $\mathrm{mM}$ ) of valproate.

Metabolomics of hES cells and hNP, does, however, point to key neurobiology pathways as a major target of valproate activity. The annotated small molecules that were statistically significant (GABA, kynurenine, and glutamate derivatives) amongst thousands of mass features, are directly implicated in neurodevelopment. Establishment of a human metabolic phenotype during neurodevelopment may contribute to deciphering and perhaps one day preventing the occurrence of birth defects associated with prenatal AED exposure (37). 


\section{CEZAR ET AL.}

\section{CONCLUSIONS}

The present study demonstrates proof of concept for $\mathrm{hES}$ cell metabolomics as a means to identify small molecules secreted by hES cells. The metabolomics strategy decribed here may serve to: (1) determine biochemical pathways that participate in the ontogenesis of developmental abnormalities and disease and (2) provide an unbiased source of candidate biomarkers for in vitro preclinical safety evaluation of pharmaceuticals such as AEDs.

A new generation of models with greater predictive power of human response is strongly warranted because lack of toxicity in animal models can sometimes lead to catastrophic results (50). In addition, this approach may detect detrimental effects of environmental (heavy metals, industrial waste products) and nutritional chemicals (alcohol) on human development. The integration of chemical biology with hES cell technology offers groundbreaking opportunities to strengthen our understanding of human development and disease susceptibility.

Because metabolomics is a relatively new "omics" science, many challenges remain in order to consolidate its full potential. Fifty percent or greater of mass features are not annotated in public databases. This limitation markedly delays the association of metabolic phenotypes to biological response. Deciphering chemical structures to identify small molecules is labor intensive and time consuming, requiring NMR spectroscopy and/or MS-MS. Execution of NMR and MS-MS, in turn, demands highly specialized training, and complex instrumentation and is generally not available to a large number of biomedical research laboratories. LC-MS instruments with increased sensitivity to detect broad spectra of polar and nonpolar compounds in low abundances, such as TOFs, are also extremely costly. Nonetheless, because metabolites are obligatory intermediate or end products in cellular responses to environmental or disease insults, metabolomics should confer a key insight into these processes that is not possible by other means-for example, the establishment of biological networks and circuits that participate simultaneously in the ontogenesis of disease or toxic response based upon unbiased, comprehensive metabolite profiling.

Our long-term, future goal is to examine the prevalence of candidate biomarkers detected here in the serum of infants affected by neurodevelopmental disorders versus healthy individuals. Specifically, we intend to measure small molecules from the hES cell metabolome in the serum of infants diagnosed with birth defects related to antiepileptics; for instance, autism spectrum disorders and spina bifida (18-20). The present study breaks new ground because it proposes a new paradigm for biomarker discovery using hES cells. hES cells are likely to provide robust mechanistic and diagnostic biomarkers in a timely manner in comparison to other cell-based models. Immortalized cells are often genetically modified and/or markedly different from endogenous counterparts; primary human cells, on the other hand, have a very short lifespan in vitro and are highly variable because they originate from cadaver tissue. The biomarkers discovered in hES cells and derived cell types, such as hNPs, following valproate exposure may also serve for prenatal screening - a well-established method to both predict and reduce the number of birth defects. Ultimately, biochemical pathways revealed by metabolomics of hES cells may provide new targets for the treatment of neurodevelopmental disorders. In addition, these pathways may reveal alternatives for prenatal dietary supplementation as a means to prevent or reduce the severity of valproate-related neurodevelopmental disorders; as is the case for folic acid and neural tube defects.

\section{SUMMARY POINTS}

- Small molecules from hES cells and hNPs are detected and identified by LC-ESI-TOF mass spectrometrybased metabolomics.

- The chemical identity of hundreds of metabolites detected in both hES cells and hNPs is still unknown.

- Exposure of hES cells to the antiepileptic valproate induces measurable and significant changes in the cellular metabolome.

- Small molecules in the kynurenine and glutamate metabolic pathways are upregulated in response to valproate in hES cells and hNPs and may serve as candidate biomarkers for developmental toxicity.

- Rate-limiting enzymes in the catabolism of tryptophan to kynurenine and serotonin synthesis from tryptophan are expressed in hES cells.

- Valproate treatment induces upregulation of TDO2, the rate-limiting enzyme that initiates the conversion of tryptophan to kynurenine.

- Metabolomics of hES cells and derivatives may serve as a novel means to discover predictive biomarkers for efficacy and safety assessment of pharmaceuticals.

\section{ACKNOWLEDGMENTS}

We are most grateful to Tori Baron (WiCell Research Institute) for immunohistochemistry during initial studies and Dr. Travis Berggren (WiCell Research Institute) for advice and critical support of LC-MS experiments. The authors would also like to thank Drs. Susan Smith, Michael Sussman, Adrian Hegeman, Ed Hutlin, and Amy Harms (University of Wisconsin-Madison) for invaluable discussions and encouragement. This work was partially 


\section{METABOLOMICS IDENTIFICATION OF hES CELLS SMALL MOLECULES}

supported by a Draper Technology Innovation Fund (TIF) Grant, The Graduate School, University of Wisconsin-Madison.

\section{REFERENCES}

1. Thomson JA, J Itskovitz-Eldor, SS Shapiro, MA Waknitz, JJ Swiergiel, VS Marshall and JM Jones. (1998). Embryonic stem cell lines derived from human blastocysts. Science 282:1145-1147.

2. Reubinoff BE, MF Pera and CY Fong. (2000). Embryonic stem cell lines from human blastocysts: somatic differentiation in vitro. Nature Biotechnol 18:399-404.

3. He JQ, Y Ma, Y Lee, JA Thomson and TJ Kamp. (2003). Human embryonic stem cells develop into multiple types of cardiac myocytes: action potential characterization. Circ Res 93:32-39.

4. Keirstead HS, G Nistor, G Bernal, M Totoiu, F Cloutier, K Sharp and O Steward. (2005). Human embryonic stem cell-derived oligodendrocyte progenitor cell transplants remyelinate and restore locomotion after spinal cord injury. J Neurosci 25:4694-4705.

5. Zhang SC, M Wernig, ID Duncan, O Brustle and JA Thomson. (2001). In vitro differentiation of transplantable neural precursors from human embryonic stem cells. Nature Biotechnol 19:1129-1133.

6. Fiehn O, J Kopka, P Dormann, T Altmann, RN Trethewey and L Willmitzer. (2000). Metabolite profiling for plant functional genomics. Nature Biotechnol 18:1157-1161.

7. Nicholson JK, J Connelly, JC Lindon and E Holmes. (2002). Metabonomics: a platform for studying drug toxicity and gene function. Nature Rev Drug Discov 1:153161.

8. Groenen PM, UF Engelke, RA Wevers, JC Hendriks, TK Eskes, HM Merkus and RP Steegers-Theunissen. (2004). High-resolution 1H NMR spectroscopy of amniotic fluids from spina bifida fetuses and controls. Eur J Obstet Gynecol Reprod Biol 112:16-23.

9. Perroud B, J Lee, N Valkova, A Dhirapong, PY Lin, O Fiehn, D KÅlt and RH Weiss. (2006). Pathway analysis of kidney cancer using proteomics and metabolic profiling. Mol Cancer 5:64-69.

10. Want EJ, BF Cravatt and G Siuzdak. (2005). The expanding role of mass spectrometry in metabolite profiling and characterization. ChemBioChem 6:1941-1951.

11. Enke CG. (1997). A predictive model for matrix and analyte effects in electrospray ionization of singly-charged ionic analytes. Anal Chem 69:4885-4893.

12. Soga T, R Baran, M Suematsu, Y Ueno, S Ikeda, T Sakurakawa, Y Kakazu, Y Ishikawa, M Robert, T Nishioka and M Tomita. (2006). Differential metabolomics reveals ophthalmic acid as an oxidative stress biomarker indicating hepatic glutathione consumption. J Biol Chem 281:1676816778.

13. Rooney WD, RG Miller, D Gelinas, N Schuff, AA Maudsley and MW Weiner. (1998). Decreased N-acetylaspartate in motor cortex and corticospinal tract in ALS. Neurology 50:1800-1805.
14. Mitsumoto H, AM Ulug, SL Pullman, CL Gooch, S Chan, MX Tang, X Mao, AP Hays, AG Floyd, V Battista, J Montes, S Hayes, S Dashnaw, P Kaufmann, PH Gordon, J Hirsch, B Levin, LP Rowland, DC Shungu. (2007). Quantitative objective markers for upper and lower motor neuron dysfunction in ALS. Neurology 68:1402-1410.

15. Lindhout D and JG Omtzigt. (1994). Teratogenic effects of antiepileptic drugs: implications for the management of epilepsy in women of childbearing age. Epilepsia 35(Suppl 4):S19-S28.

16. Eriksson K, K Viinikainen, A Monkkonen, M Aikia, P Nieminen, S Heinonen and R Kalviainen. (2005). Children exposed to valproate in utero-population based evaluation of risks and confounding factors for long-term neurocognitive development. Epilepsy Res 65:189-200.

17. Vinten J, N Adab, U Kini, J Gorry, J Gregg and GA Baker. (2005). Liverpool and Manchester Neurodevelopment Study Group. Neuropsychological effects of exposure to anticonvulsant medication in utero. Neurology 64:949954.

18. DiLiberti JH, PA Farndon, NR Dennis and CJ Curry. (1984). The fetal valproate syndrome. Am J Med Genet 19:473-481.

19. Ornoy A. (2006). Neuroteratogens in man: An overview with special emphasis on the teratogenicity of antiepileptic drugs in pregnancy. Reprod Toxicol 21:436-445.

20. Williams G, J King, M Cunningham, M Stephan, B Kerr and JH Hersh. (2001). Fetal valproate syndrome and autism: additional evidence of an association. Dev Med Child Neurol 43:202-206.

21. Rasalam AD, H Hailey, JH Williams, SJ Moore, PD Turnpenny, DJ Lloyd, and JC Dean. (2005). Characteristics of fetal anticonvulsant syndrome associated autistic disorder. Dev Med Child Neurol 47:551-555.

22. Adab N, U Kini, J Vinten, J Ayres, G Baker, J ClaytonSmith, H Coyle, A Fryer, J Gorry, J Gregg, G Mawer, P Nicolaides, L Pickering, L Tunnicliffe and DW Chadwick. (2004). The longer term outcome of children born to mothers with epilepsy. J Neurol Neurosurg Psychiatry 75:15751583.

23. Kalyani A, K Hobson and MS Rao. (1997). Neuroepithelial stem cells from the embryonic spinal cord: isolation, characterization and clonal analysis. Dev Biol 186:13891399.

24. Zhang SC. (2006). Neural subtype specification from embryonic stem cells. Brain Pathol 16:132-142.

25. Greaves P, A Williams and M Eve. (2004). First dose of potential new medicines to humans: how animals help. Nature Rev Drug Discov 3:226-236.

26. Candenas M, R Villa, R Fernandez Collar, MJ Moina, S Pintado, F Garcia Saez and FV Alvarez. (1995). Maternal serum alpha-fetoprotein screening for neural tube defects. Report of a program with more than 30000 screened pregnancies. Acta Obstet Gynecol Scand 74:266-269.

27. Ludwig TE, V Bergendahl, ME Levenstein, J Yu, MD Probasco, JA Thomson. (2006). Feeder-independent culture of human embryonic stem cells. Nature Methods 3:637-646.

28. Muotri AR, K Nakashima, N Toni, VM Sandler and Gage. (2005). Development of functional human embryonic stem 


\section{CEZAR ET AL.}

cell-derived neurons in mouse brain. Proc Natl Acad Sci USA 102:18644-18648.

29. Eikel D, A Lampen and H Nau. (2006). Teratogenic effects mediated by inhibition of histone deacetylase: evidence from quantitative structure activity relationships of 20 valproic acid derivatives. Chem Res Toxicol 19:272-278.

30. Bowden CL. (2007). Spectrum of effectiveness of valproate in neuropsychiatry. Expert Rev Neurother 7:9-16.

31. Bristow AWT and KS Webb. (2003). Intercomparison study of accurate mass measurement of small molecules in mass spectrometry. J Am Soc Mass Spectrom 14:10861098.

32. Hsieh J, K Nakashima, T Kuwabara, E Mejia and FH Gage. (2004). Histone deacetylase inhibition-mediated neuronal differentiation of multipotent adult neural progenitor cells. Proc Natl Acad Sci USA 101:6659-16664.

33. Laeng P, RL Pitts, AL Lemire, CE Darabik, A Weiner, G Tang, R Thyagarajan, BA Mallon and CA Altar. (2004). The mood stabilizer valproic acid stimulates GABA neurogenesis from rat forebrain stem cells. J Neurochem 91:238-251.

34. Miyazaki K, N Narita and M Narita. (2005). Maternal administration of thalidomide or valproic acid causes abnormal serotonergic neurons in the offspring: implication for pathogenesis of autism. Int J Devl Neurosci 23:287-297.

35. Wu J and H McAllister. (2003). Exact mass measurement on an electrospray ionization time-of-flight mass spectrometer: error distribution and selective averaging. J Mass Spectrom 38:1043-1053.

36. Munn DH, M Zhou, JT Attwood, I Bondarev, SJ Conway, B Marshall, C Brown and AL Mellor. (1998). Prevention of allogeneic fetal rejection by tryptophan catabolism. Science 281:1191-1193.

37. Wyszynski DF, M Nambisan, T Surve, RM Alsdorf, CR Smith, LB Holmes and Antiepileptic Drug Pregnancy Registry. (2005). Increased rate of major malformations in offspring exposed to valproate during pregnancy. Neurology 64:961-965.

38. Manent JB, I Jorquera, I Mazzucchelli, A Depaulis, E Perucca, Y Ben-Ari and A Represa. (2007). Fetal exposure to GABA-acting antiepileptic drugs generates hippocampal and cortical dysplasias. Epilepsia 48:684-693.

39. Rogawski MA and W Loscher. (2004). The neurobiology of antiepileptic drugs. Nature Rev Neurosci 5:553-564.

40. Nabi R, FJ Serajee, DC Chugani, H Zhong and AH Huq. (2004). Association of tryptophan 2,3 dioxygenase gene polymorphism with autism. Am J Med Genet B Neuropsychiatr Genet 125:63-68.
41. Persico AM and T Bourgeron T. (2006). Searching for ways out of the autism maze: genetic, epigenetic and environmental clues. Trends Neurosci 29:349-358.

42. Viinikainen K, K Eriksoon, A Monkkonen, M Aikia, P Nieminen, S Heinonen and R Kalvianinen. (2006). The effects of valproate exposure in utero on behavior and the need for educational support in school-aged children. Epilepsy Behav 9:636-640.

43. Kocki T, M Wielosz, WA Turski and EM Urbanska. (2006). Enhancment of brain kynurenic acid production by anticonvulsants-Novel mechanism of antiepileptic activity? Eur J Pharmacol 41:147-151.

44. Vriend JP and NA Alexiuk. (1996). Effects of valproate on amino acid and monoamine concentrations in striatum of audiogenic seizure-prone Balb/c mice. Mol Chem Neuropathol 27:307-324.

45. Stone TW and LG Darlington. (2002). Endogenous kynurenines as targets for drug discovery and development. Nature Rev Drug Discov 1:609-620.

46. Dikranian K, MJ Ishimaru, T Tenkova, J Labruyere, YQ Qin, C Ikonomidou and JW Olney. (2001). Apoptosis in the in vivo mammalian forebrain. Neurobiol Dis 8:359379.

47. Nachmany A, V Gold, A Tsur, D Arad and D Weil. (2006). Neural tube closure depends on nitric oxidase synthase activity. J Neurochem 96:247-253.

48. Murabe M, J Yamauchi, Y Fujiwara, M Hiroyama, A Sanbe and A Tanoue. (2007). A novel embryotoxic estimation method of VPA using ES cells differentiation system. Biochem Biophys Res Commun 352:164-169.

49. Pellizzer C, S Bremer and T Hartung. (2005). Developmental toxicity testing from animal towards embryonic stem cells. ALTEX 22:47-57.

50. Sheridan, C. (2006). TeGenero fiasco prompts regulatory rethink. Nature Biotechnol 24:475-476.

Address reprint requests to:

Dr. Gabriela G. Cezar

Department of Animal Sciences,

University of Wisconsin-Madison

1675 Observatory Drive

Madison, WI 53706

E-mail: ggcezar@wisc.edu

Received February 4, 2007; accepted August 21, 2007. 